and storage of liquefied gases, a field which is expanding rapidly. Again, however, there are few references to conventional refrigeration, where safety still needs emphasizing for both installer and user.

Another section, which many will find useful, contains a literature and information roference. Here, biblio. graphies, handbooks, data books, standards and directories are listed with brief descriptions.

A general criticism of a work of this type is, of course, that it is bound to be out of date. Cryogenic techuology is developing at an extraordinary rate, due partially to the various space programmes, and even techniques used in conventional refrigeration tend to change quite rapidly. A bibliography must take a considerable time to compile and to publish, so its most recent references are two to three years earlier than its publication date. With this in mind, it must be appreciated that the value of this book lies in its ability to indicate the vast background of international literature available for anyone pursuing one of the topics covered. In this way, it can have immense value, and would undoubtedly save many hours of possibly abortive library work.

D. R. ScotT

\section{BIRTH CONTROL FOR JOURNALS?}

\section{Advances in Molecular Relaxation Processes}

Vol. 1, No. 1; November 1967. Editors: W. J. OrvilleThomas, J. Meixner and C. J. F. Böttcher. Published quarterly by Elsevier, Amsterdam. $£ 109 \mathrm{~s} .6 \mathrm{~d}$. per vol.

THe arrival on my desk of the first number of yet another new journal makes me wonder if the civilization in the book Fahrenheit 45I, which banned the printed word, was so outrageous after all. Those who are subjected to the hail of new journals will also sympathize with the psychologist, Nevitt Sanford, who considers that academic man is suffocating under the deluge of printed words and has predicted that in time "the most prestigious colleges will forbid their professors to publish until they have been on the faculty for five years".

A new journal such as this one can scarcely be faulted when considered on its own. Its terms of reference are that it is "devoted to the study of the phenomena of viscoelasticity and acoustic, dielectric and magnetic relaxation", and I, of all people, can scarcely claim that this is not a most important, integrated and valid field of study. If it manages to attract good articles in this field it will be very convenient to mo and to many of my colleagues-indeed, I must hasten to write an article for it in case someone in the field forgets that I am one of the experts, and so it goes on. What is so worrying is that shortly a young man will rush in to persuade me that this is a very appropriate journal for us and that we must tako out a subscription. This has now happened! He does not realize that all the articles we have seen so far could well have been placed elsewhere in established respectable review journals, and even in "Advances ..." which started to advance before this one, and at least we already get those in the library. Since this is undoubtedly a convenient journal perhaps we ought to get it, but in order to pay for it is anyone willing to give up any of the journals we get already? Not on your life! There is the difficulty; the new journals pour in but the money does not increase. The UGC says we have to find money for such increased activities from increases in "productivity" and how do we do that in the library? Would it be heretical for me to say to the young man that he should just look a, the abstracts and get the article if he needs it? No, that will not do, it must all be there in pristine newness the moment the latest issue comes out and subsequently stored and forgotten at great cost. Surely this ridiculous charade has gone on long enough and we should increase our productivity enormously at one go by the United Kingdom buying one copy only of any new journal and distributing Xerox copies of articles to those who really want them. Would we then see so many new journals published ? Perhaps we would even then because I have been told that such journals do not make much money for editor or publisher. It is said that some journals even run for years at a loss and so it is very nice of them to edit and publish our writing for us at no charge.

I must warn you that the raison d'etre of the journal, if you wish to know it, is curiously placed in Volume 1, No. 1, between pages 68 and 69 as part of an announcemont of another new journal !

Just in case you wish to consider whether this new journal is of interest to you and to borrow it from Harrogate, the contents of this issue are as follows: "Dielectric Rolaxation by Intramolecular Mechanisms" by C. P. Smyth; "Stochastic Theory of Multistate Relaxation Processes" by I. Oppenheim, K. E. Shuler and G. H. Weiss; and "Relaxation Processes in Gases" by $\mathbf{P}$. Borrell. Volume 1, No. 2, will include: "Structural Relaxation in Water" by C. M. Davis and J. Jarzynski; and "Nuclear Magnetic Resonance Relaxation of Moleeules Adsorbed on Surfaces" by H. A. Resing. J. G. Powles

\section{POLYMERS}

\section{Polymer Systems}

Deformation and Flow. (Proceedings of the 1966 Annual Conference of the British Society of Rheology.) Edited by R. E. Wetton and R. W. Whorlow. Pp. ix +338 . (London: Macmillan and Co., Ltd., 1968.) 70s. net.

THis book presents the proceedings of the 1966 conference of the British Society of Rheology. The twenty-nine papers range over such varied subjects as rubber deformation, elasticity of textile fibres, filled polymers and many types of behaviour, such as melt flow instability, expansion and contraction at plane and circular jets, important in industrial applications. The basic theme which runs through the papers is the relationship betwcen the mechanical properties of polymers in terms of molccular structure, and, broadly, the papers fall into three classes. The first class deals with the phenomenological description of mechanical properties and the related problem of converting experimental data from one form of description to another, which may be more eonvenient for a moleculas interpretation or for practical purposes. The second class of papers deals chiefly with attempts to dorive relationships between mechanical properties and structure. There is also a third class of papers which is concerned solely with changes in molecular structure which are related to deformation and flow in polymer systems and not with details of associated mechanical properties.

A valuable feature of the publication is the two introductory lectures on "Deformation of High Polymer Solids" by I. M. Ward and "Rheological Properties of Polymer Solutions" by L. R. G. 'Treloar. The breadth of coverage of the papers is much wider than the title of the book implies and only brief reference can be made to the range of subjects covered. In the sections on solids already referred to, there are important papers on deformation and viscoelastic phenomena in networks, the: effects of crystallization under stress (which relates to the controversy over the past few years concerning the structure of extruded polyethylene film) and the effects of crystal morphology on rheological behaviour. In the section on liquids the properties of highly viscous systems and dilute solutions are considered together with several papers on the use of the rheogoniometer for investigating the properties of polymer solutions. Other contributions deal with such topics as the generation of free radicals by high strains, the creep properties of wood, PVC plasticizer systems and the rheological properties of carbohydrate solutions. 